\title{
The Release of Compounds from Microbial Cells
}

\author{
Marek Solecki \\ Technical University of Lodz \\ Poland
}

\section{Introduction}

Compounds present in the microbial cells are of great commercial value. Their separation requires disintegration of cell walls and cytoplasmic membranes. The disintegration of microorganisms on an industrial scale is carried out, among the others, in bead mills (Chisti \& Moo-Young, 1986; Geciowa et al., 2002; Hatti-Kaul \& Mattiasson, 2003). A bead mill is a container filled with beads that are set in circular motion by a rotating stirrer. Microorganisms dispersed in the liquid are disrupted due to the impact of beads. The mechanism of cell destruction is a result of combined action of normal and tangential forces. There are three basic types of this mechanism: collisions of beads, grinding and rolling performed by the beads. Disintegration is a very complex process. In this process, cell walls of microorganisms are disrupted, intracellular compounds are released and dissolved in the continuous phase, cell walls are subjected to microgrinding, the released macromolecular compounds are cut and the released enzymes interact. Rheological properties of the suspension and its continuous phase are changed.

Currie et al. (1974) described disintegration kinetics of microorganisms in the bead mill. The authors developed a linear model by comparing experimental data with results obtained during the disintegration process carried out in a high-pressure homogenizer (Hetherington et al., 1971). A logical model based on the analogy to the theory of gas kinetics was proposed by Melendres et al. (1998). They presumed that microorganisms could be destroyed due to collisions of dispersed beads of the packing. A phenomenological model based on the flow of suspension between two volumes was developed by Heim \& Solecki (1998). The authors assumed that cells were disrupted while moving from a safe volume to the one in which no living microorganisms could exist. Basing on the sequence of events: cell disruption - the release of intracellular compounds, Melendres et al. (1993) developed a nonlinear model of the release of selected intracellular enzymes. Heim et al. (2007) described nonlinearity of the kinetics caused by changes in the disintegration conditions which was a result of the process run. Nonlinearity of the disintegration process resulting from subsequent decline of the biggest fractions of yeast cells was observed by Solecki (2009). Earlier, Whitworth (1974) described nonlinearity of cell disintegration kinetics in a suspension containing microorganisms (Candida lipolytica) which belonged to the same species and occurred in two morphological forms. The recently developed theory of random transformations of dispersed matter makes it possible to include in the description the fundamental phenomena observed during the process (Solecki, 2011). The aim of the study was to 
develop, basing on this theory, a phenomenological model of microorganism disintegration in a bead mill and to present a mathematical description of the process which would include the effect of cell size on the rate of cell disintegration.

\section{Theory}

A basis for the theory of random transformations of dispersed matter and principles of constructing general phenomenological and mathematical models were presented by Solecki (2011). In the case of disintegration of microorganisms in bead mills, a material medium $\mathrm{V}(\tau)$ is a suspension of microorganisms which fills the working mill chamber. The concept of material objects belonging to set $N$ covers microbial cells dispersed in the liquid. A random transformation consists in cell disruption between circulating elements of the packing and release of intracellular compounds.

Basic conditions prevailing in space $\mathrm{V}$ of the mill chamber are safe for microbial cells. The process of random transformation of objects belonging to set $N$ proceeds as follows.

In any instant $\tau(\tau \geq 0)$, p families of transformation volumes $V_{\gamma j}$ dispersed in space $V$ are generated at random, where $p$ is the natural number. During the process the number of generated families of volumes $V_{\gamma j}$ is big and can change in time according to Eq. (1).

$$
p=f_{3}(\tau)
$$

Volume $\mathrm{V}_{\mathrm{\gamma} j \mathrm{i}}$ is the transformation space of the i-th cell of dispersed microorganisms which belongs to the $\mathrm{j}$-th family. A set of the conditions in which a transformation proceeds at the intensity no less than $\gamma_{\mathrm{ti}}$, occurring in this volume, will ensure the transformation of the i-th object from set $N$. The transformation consists in the change $\varsigma$ of cell properties $(\varsigma>0)$ belonging to the set of identified properties of microorganisms Pr. After the transformation an object from set $N$ does not belong to set $N$ any longer. In the case of disintegration of microbial cells in a bead mill, the set of systemic transformation conditions is limited mainly to the transforming action of mechanical factors. According to Eq. (2), space $\mathrm{V}$ is

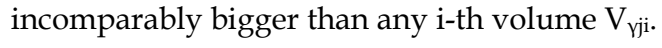

$$
V_{\gamma j i}<<
$$

The range of changes in transformation volumes $\mathrm{V}_{\mathrm{\gamma ji}}$ generated in space $\mathrm{V}$ is described by Eq. (3) in reference to the volume, and by Eq. (4) in view of the intensity of transformation conditions.

$$
\begin{gathered}
\left(V_{\gamma j i}\right)_{\min } \leq V_{\gamma j i} \leq\left(V_{\gamma j i}\right)_{\max } \\
V_{\gamma j i\left(\gamma_{t}=\gamma_{t i}\right)} \leq V_{\gamma j i\left(\gamma_{t}\right)} \leq V \gamma_{\gamma j i\left(\gamma_{t}=\gamma_{\max }\right)}
\end{gathered}
$$

Symbol $\gamma$ tmax denotes the highest intensity of transformation conditions which can be generated in space $\mathrm{V}$.

As a result of relative movement, the $i$-th cell is introduced to appropriate transformation volume $\mathrm{V}_{\gamma \mathrm{\gamma j}}$. This volume is limited by surface $\mathrm{F}_{\gamma \alpha \mathrm{ji}}$ belonging to it according to Eq. (5).

$$
F_{\gamma \alpha j i} \in V_{\gamma j i}
$$


On the other hand, volume $V_{\gamma j i}$ can be limited by surface $F_{\gamma \beta j i}$ when it is formed. This surface belongs to the transformation volume according to Eq. (6).

$$
F_{\gamma \beta j i} \in V_{\gamma j i}
$$

The i-th object is transformed immediately after translocation of all its points to the transformation volume $\mathrm{V}_{\gamma \mathrm{ji}}$. If volume $\mathrm{V}_{\mathrm{\gamma j \textrm {i }}}$ is bigger than the volume of the $\mathrm{i}$-th object, then volume $\mathrm{V}_{\beta \mathrm{ji}}$ is formed in it. It is limited by surface $\mathrm{F}_{\gamma \alpha \mathrm{ji}}$ which does not belong to it according to Eq. (7)

$$
F_{\gamma \alpha j i} \notin V_{\beta j i}
$$

Space $\mathrm{V}_{\beta \mathrm{ji}}$ cannot include total unconverted material object belonging to set $N$ for which an appropriate transformation volume is $V_{\gamma j \mathrm{ji}}$. Before being translocated to $\mathrm{V}_{\beta \mathrm{ji}}$, every $\mathrm{i}$-th object must be first transformed in volume $\mathrm{V}_{\mathrm{\gamma j \textrm {j }}}$.

Volume $\mathrm{V}_{\alpha \mathrm{i}}$ is safe for the unconverted i-th object from set $N$. We assume that intensive stirring takes place in it. Its aim is to make the concentration of unconverted objects from set $N$ uniform within appropriate volumes which are safe for them. Volume $\mathrm{V}_{\alpha \mathrm{i}}$ is composed of two parts: $V_{\text {ait }}$ which is part of volume $V_{\alpha i}$ whose subsets can be transformed to volumes $V_{\gamma i}$ or $\mathrm{V}_{\beta}$; and $\mathrm{V}_{\text {aic }}$ which is part of volume $\mathrm{V}_{\alpha \mathrm{i}}$ whose subsets are never transformed to other volumes. In the case of the bead mill, volumes $V_{\text {aic }}$ occur near all surfaces of the working chamber. These volumes are distant from the mill surface by the size of a cell, and the thickness of their layer is slightly smaller than the radius of the smallest bead in the packing. In volume $V_{\text {aic }}$ the $\mathrm{i}$-th cell is fully safe. The quotient of volumes $V_{\text {aic }}$ to $V_{\text {ai }}$, the quotient of the sum of volumes $V_{\gamma i}$ and $V_{\beta i}$ to $V_{\alpha i t}$ and the rate of relative movement of the i-th cell to $V_{\gamma i}$ are the factors that determine efficiency of the system of transformation of the i-th cell in a given technical device. An increase of the first factor causes a decrease of the transformation efficiency. An opposite effect is caused by an increase of other factors.

For instance, studies were carried out to increase differences in the velocity of points on the surfaces of adjacent beads of the packing which circulates in the mill (Solecki, 2007). Such an effect was to be induced by the presence of immobile baffles between stirring disks of a classical mill. In many cases of geometric solution of the mill interior, because of introduction of the baffles the efficiency of microorganism disintegration was deteriorated (Solecki, 2007). The development of a narrow-clearance construction did not bring about elimination of classical mills equipped with multi-disk impellers from the market. Rate constants determined for the process of disintegration in the mill with a bell-shaped impeller were often lower than those determined for a classical mill in comparable process conditions (Solecki, 2007). Optimum operating conditions of narrow-clearance mills are obtained for smaller values of packing degree. In the case of a classical mill it is about $90 \%$, while for the mill with a bell-shaped impeller $60 \%$, and with a cylindrical stirrer only $40 \%$.

Part of space $\mathrm{V}$ is composed of volume $\mathrm{V}_{\delta}$ which is safe for microorganisms from set $N$ (Solecki, 2011). No stirring takes place in it and neither it nor its subsets are transformed to other volumes. Between volumes $\mathrm{V}_{\alpha}$ and $\mathrm{V}_{\delta}$ microbial cells can migrate freely. For a correctly constructed mill chamber, volumes $\mathrm{V}_{\delta}$ (these can be slots in the place where two elements meet) are negligibly small and insignificant from the technology point of view, particularly when the device is sterilized between subsequent processes. In further studies it was assumed that $\mathrm{V}_{\delta}=0$. 
An ellipsoidal shape of microorganisms and their different sizes were assumed. The size of the $\mathrm{i}$-th cell is described by the length of three mutually perpendicular axes $c_{1 i}, c_{2 i}$ and $c_{3 i}$, which satisfy relation (8).

$$
c_{1 i}=c_{2 i} \leq c_{3 i}
$$

Microorganisms were assumed to be much smaller than packing elements in the mill $d_{k}$ according to Eq. (9).

$$
c_{3 i}<<d_{k}
$$

For the whole population of microorganisms subjected to disintegration it was assumed initially that cell walls had the same mechanical strength and that the compressibility of fluids protected by them was identical.

Microorganisms in the working mill chamber are disintegrated between two surfaces belonging to different solids. One of them is a single element of the packing, and the other one is another element of the packing or an element of the mill working chamber. This can be the external surface of the reservoir of diameter $D_{z}$, the surface of an impeller with disk diameter $d_{t}$ or of its shaft of diameter $d_{w}$. Due to the relations in Eq. (9) through (12), it was assumed that all inner surfaces of the mill chamber and stirrer were planes.

$$
\begin{aligned}
& d_{k}<<D_{z} \\
& d_{k}<<d_{w} \\
& d_{k}<<d_{t}
\end{aligned}
$$

It was assumed that microorganisms were destroyed as a consequence of disruption of cell walls caused mainly by compressive load which acted along the shorter cell axis $c_{1 i}$. This assumption was made after analysis of the results of many experiments which included disruption of single yeast cells using micro-tools controlled by micromanipulators. Results of these experiments have not been published yet. Non-homogeneity of the structure, thickness and rigidity of cell walls causes that microorganisms compressed along the long axis are deformed asymmetrically and due to accumulated energy catapult from the hazardous zone. This property formed by the evolution guarantees a better survival rate of microorganisms in their environment. In the case of actions characterized by much higher dynamics than the typical one occurring in nature, the probability of cell destruction along the long axis can be significant. In such a case the above assumption simplifies the problem. It is assumed that cell walls are disrupted when compounds inside the cell can flow out of it. This state is equivalent to cell disintegration - transformation of the object. Three stages are distinguished in the destruction of microorganisms (Solecki, 2009):

1. contact,

2. cell deformation,

3. disruption of cell walls.

At the first stage the cell of axis $c_{1 i}$ contacts two destroying surfaces. The cell is not deformed. Points of contact of solid bodies with the i-th cell are called the points of destruction. They form a single destruction system. The segment which connects destruction points of cell $\mathrm{c}_{1 \mathrm{i}}$ is defined as the destruction axis. At the second stage, when destroying 
surfaces approach each other, the cell is deformed. The contact area of the cell with solid bodies described by diameter $\mathrm{d}_{\delta \mathrm{i}}$ increases. Walls of the cell with axis $\mathrm{c}_{1 \mathrm{i}}$ are disrupted when compression surfaces approach each other at the third stage to destruction distance $1_{\delta i \min }$ described by the relation given in Eq. (13).

$$
l_{\delta i \min }<c_{1 i}
$$

From the point of view of random transformation, the first two destruction stages have no significance, providing naturally that the number of load cycles has no effect on the cell strength. Hence, it can be assumed that starting with instant $\tau=0$, all cells present in the suspension are so deformed that an arbitrarily small increase of deformation in the transformation volume causes their disruption. The distance of destruction is measured along the destruction axis. It was assumed that the cell-destroying surface contact area in the moment of cell wall disruption was represented by a spherical cap of diameter $\delta_{\mathrm{i} \text { max }}$.

Disruption of cells dispersed in the liquid occurs once the cells have been translocated to destruction volume $\mathrm{V}_{\mathrm{\gamma ji}}$ which is in the place of formation of a single destruction system. The continuity of grinding surfaces was assumed for the set of points belonging to circular environment of diameter $\delta_{\mathrm{i} \text { max }}$ around the point of destruction. At least one grinding surface has a spherical shape. Thus, in the mill two destruction elements can generate a single destruction axis or a set of axes which constitute a cylindrical surface. At the present stage of studies we make a simplified assumption that elements destroying microbial cells are perfectly rigid.

We consider the case of batch mill operation, when during the process the supply of microbial suspension is constant. Its volume is equal to $\mathrm{V}$. The process is carried out for the known initial biomass concentration. The initial number of microorganisms is $\mathrm{N}_{0}$. During the process no microbial cells are added from the outside (it is assumed that the disintegration process is carried out in sterile conditions) and no cells are removed to the outside. The time of disintegration is very short as compared to the life time of microorganisms and the time of formation of new cells in the process conditions. Hence, it can be assumed that function $\mathrm{f}_{13}$ which describes cell growth and function $\mathrm{f}_{14}$ describing elimination of cells different than that being a result of the transformation, satisfy equations (14) and (15).

$$
\begin{aligned}
& f_{13}\left(N_{0}, \tau\right)=0 \\
& f_{14}\left(N_{0}, \tau\right)=0
\end{aligned}
$$

In the case of disintegration of microorganisms in the bead mills the transformation consists in the disruption of microbial cell walls. In the process carried out in the bead mill, high levels of packing of the mill chamber and big rotational speed of the stirrer are applied. Because of a high level of packing the mill with beads and high intensity of their circulation resulting from high rotational speed of the stirrer, it was assumed that during the process:

1. the sum of all volumes $\mathrm{V}_{\mathrm{\gamma i}}$ is constant (Eq. (16)),

$$
\bigcup_{i=1}^{n} V_{\gamma j i}=\text { const }
$$


2. the sum of all volumes $\mathrm{V}_{\beta \mathrm{i}}$ is constant (Eq. (17)).

$$
\sum V_{\beta i}=\text { const }
$$

We also assume that the process of microbial disintegration is carried out in steady-state conditions during the whole process duration. The mill start-up is neglected.

\section{A phenomenological model}

Figure 1 shows a theoretical set of possibilities to generate the families of transformation volumes between two spherical surfaces. It is prepared on the basis of a description of the general phenomenological model presented by Solecki (2011).

Single microbial cells are reduced to material points which have, among the others, such properties as spatial shape, volume, mass, etc. On each vertical segment between $\overline{A C}$ and $\overrightarrow{B D}$, division of volume $\mathrm{V}(\tau)$ is marked. This division is a result of forming transformation volume $V_{\mathrm{yji}}$ for the $\mathrm{i}$-th cell. We consider an arbitrary vertical segment $\overline{15}$. It is divided by dashed lines $\overline{R S}, \overline{G H}$ and $\overline{I J}$ into four main parts. Volume $\mathrm{V}_{\alpha \mathrm{ci}}$ which is safe for cell $\mathrm{N}_{\mathrm{i}}$ occupies interval $\langle 1,2)$. In this volume intensive stirring takes place. Neither the whole volume $\mathrm{V}_{\alpha \mathrm{aci}}$ nor any of its subsets can be transformed to other volumes. Interval $\langle 2,4)$ occupies volume $\mathrm{V}_{\alpha \mathrm{ti}}$. It is safe for cell $\mathrm{N}_{\mathrm{i}}$ and intensive stirring is observed in it. Subsets of volume $V_{\alpha+\mathrm{i}}$ can be transformed to volumes $\mathrm{V}_{\mathrm{\gamma ji}}$ and $\mathrm{V}_{\beta \mathrm{ji}}$. $\mathrm{V}_{\mathrm{\gamma j \textrm {i }}}$ is the transformation volume of object $\mathrm{N}_{\mathrm{i}}$ and in Fig. 1 it occupies interval $\langle 3,4\rangle$. It includes surface $\mathrm{F}_{\text {roji }}$ which separates it from volume $V_{\alpha t i}$. Volume $V_{\gamma j i}$ is also limited by surface $F_{\gamma \beta j i}$ belonging to it, in case it is formed. This occurs when $V_{\gamma j i}$ has the size big enough in relation to the object transformed in it. Volume $V_{\beta j i}$ occupies interval $(3,5\rangle$ and is inaccessible for non-transformed object $N_{i}$. Surface $F_{\gamma \alpha j i}$ which separates it from volume $V_{\alpha}$ does not belong to volume $V_{\beta j \mathrm{j}}$. It was assumed that object $\mathrm{N}_{\mathrm{i}}$ is the material point that has feature $\left(\mathrm{V}_{\gamma \mathrm{i}}\right)_{\min }$ among the others. This is the smallest transformation volume characteristic of a given object. Components of space $\mathrm{V}$ in Fig. 1 are defined by two parameters: the length of relevant vertical segments and color intensity which determines a functional relation. The family of volumes $P_{j}$ is formed of a group of transformation volumes for various material objects from set $N$ defined by segment 3'3". For objects from set $N$ of the smallest characteristic transformation volume $\left(V_{\mathrm{Ys}}\right)_{\min }$, the division into $\mathrm{V}_{\alpha \mathrm{\alpha c}}, \mathrm{V}_{\alpha \mathrm{t}}, \mathrm{V}_{\mathrm{\gamma ji}}$ and $\mathrm{V}_{\beta \mathrm{ji}}$ is marked by continuous lines $\overline{R^{\prime} S^{\prime}}, \overline{G^{\prime} H^{\prime}}$ and $\overline{I^{\prime} J^{\prime}}$. For objects with the biggest characteristic transformation volume $\left(\mathrm{V}_{\mathrm{yb}}\right)_{\min }$, the division into volumes with different properties is marked by dotted lines $\overline{R " S "}, \overline{G^{\prime \prime} H^{\prime \prime}}$ and $\overline{I^{\prime \prime} J "}$.

Like for the cell-disrupting spherical surface-spherical surface system, also for the spherical surface-plane surface system we can determine a map to generate volumes related to the cell transformation process.

To determine the set of possibilities of generating transformation volumes, it is essential to know results of morphological studies and strength tests of microorganisms dispersed in space V. The current development of computer techniques for microscopic image analysis causes that morphological studies are not a problem now. Studies on the strength of microbial cells were carried out by Mashmoushy et al. (1998), Shiu et al. (1999) and SvaldoLanero et al. (2007). In the case of the bead mill it is especially important to know destroying transformations in which cells are disrupted (Smith et al., 2000, Stenson et al., 2010). Mechanical stresses in Saccharomyces cerevisiae yeast cells caused by high hydrostatic pressure were tested by Hartman et al. (2006). Depending on the method by which the 
process is carried out and according to a technical device selected, it is necessary to know the morphology of packing in the case of vibrating mixers and bead mill, the distribution of shearing forces and velocity of liquid flow through the valve in the case of high-pressure homogenizers, and finally the size of cavitation bubbles in the case of ultrasound homogenizers.

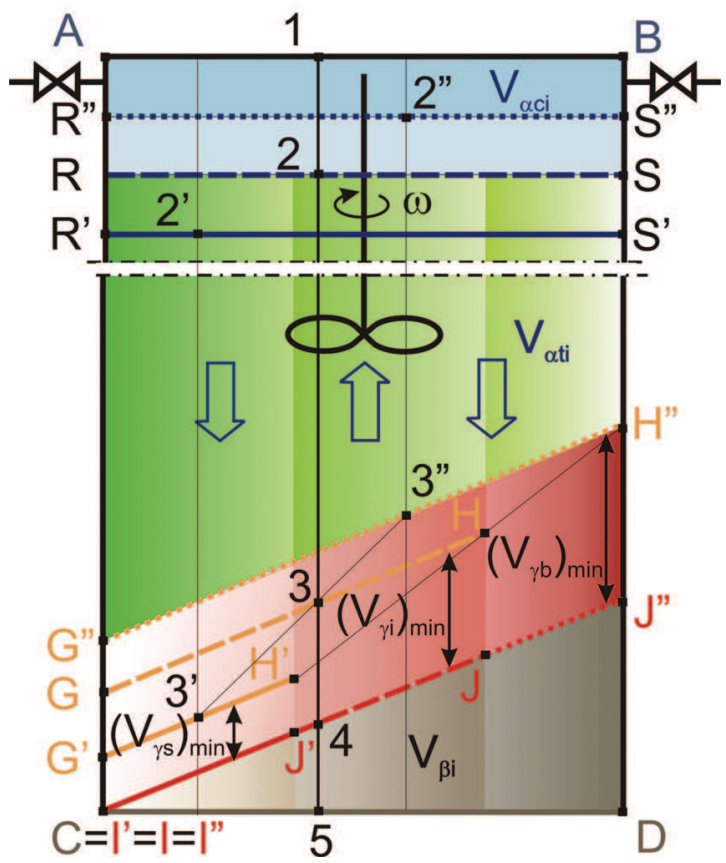

Fig. 1. The set of possibilities to generate a single family of transformation volumes and related volumes for microorganisms from set $N$ dispersed in space $\mathrm{V}$

In the case of cell disintegration in the bead mill packed with beads of the same diameter, $\mathrm{p}_{\mathrm{s}}$ families of destruction volumes are formed by the spherical surface-spherical surface transformation system and $p_{p}$ families by the spherical surface-flat surface transformation system. Numbers $p_{s}$ and $p_{p}$ are the natural numbers and their sum is equal to the number of transformation families $\mathrm{p}$ formed in space $\mathrm{V}$. The phenomenological model consists of $\mathrm{p}_{\mathrm{s}}$ layers of the first type shown in Fig. 1 and $p_{p}$ layers of the second type specific of the spherical surface-flat surface system. The range of space divisions in subsequent layers encompasses only the divisions which were formed for one specified family of transformation volumes. If, for instance, two contacting spherical surfaces generate a transformation family, then the layer encompasses space divisions for all vertical segments from point $\mathrm{H}^{\prime}$ to point $\mathrm{H}^{\prime \prime}$. On the other hand, if the distance between two spherical surfaces is such that the biggest axially compressed cell which is most susceptible to disintegration is disrupted, then in the component layer there will be a space division described (dotted lines) by the division of vertical segment passing through point $G^{\prime \prime}$. In a general case, for the i-th cell from set $N$ the component layer will contain divisions marked on vertical segments from point $3^{\prime}$ to point $3^{\prime \prime}$. The sum of all volumes contained in p layers is equal to $\mathrm{V}$. By 
analogy, phenomenological models can be constructed for other methods of microorganism disintegration: physical, chemical and biological.

In the phenomenological model of microorganism disintegration it was assumed that space $\mathrm{V}$ consisted of volumes $\mathrm{V}_{\alpha}, \mathrm{V}_{\gamma}$ and $\mathrm{V}_{\beta}$. Additionally, volume $\mathrm{V}_{\alpha}$ was divided into $\mathrm{V}_{\alpha \mathrm{t}}$ and $\mathrm{V}_{\alpha c}$. Destruction volumes $\mathrm{V}_{\mathrm{\gamma ji}}$ are formed by circulating beads of the packing. The general and specific schematics of cell disruption between spherical surfaces were discussed in an earlier study (Solecki, 2011). The general scheme of cell disruption between the spherical and flat surface is shown in Fig. 2a. It covers all possible cases contained between segments $\overline{A C}$ and $\overline{B D}$ in Fig. 1, referring to the division of the volume of microbial suspensions into $\mathrm{V}_{\alpha \mathrm{ji}}, \mathrm{V}_{\gamma \mathrm{ji}}$ and $\mathrm{V}_{\beta \mathrm{ji}}$. After limiting deformation of the i-th cell, its walls are disrupted (Fig. 2a). The formed transformation volume $V_{\gamma j i}$ is limited by surface $F_{\gamma \alpha j i}$ (orange dashed line), surface $\mathrm{F}_{\gamma \beta \mathrm{ji}}$ (red dashed line), the spherical surface of packing element and the flat surface of the mill chamber. Volume $V_{\gamma j i}$ with the axis of symmetry $O U$ includes limiting surfaces $F_{\gamma \alpha j i}$ and $F_{\gamma \beta j i}$. Surface $F_{\gamma \beta j i}$ limits volume $V_{\alpha j i}$, but it does not belong to this volume. The volume inaccessible for the $\mathrm{i}$-th living cell $\mathrm{V}_{\beta j \mathrm{i}}$ is limited by the spherical plane and surface $\mathrm{F}_{\gamma \alpha \mathrm{ji}}$. The limiting surfaces do not belong to volume $V_{\beta j \mathrm{ji}}$. The axis of symmetry of volume $\mathrm{V}_{\beta \mathrm{ji}}$ is straight line OU.
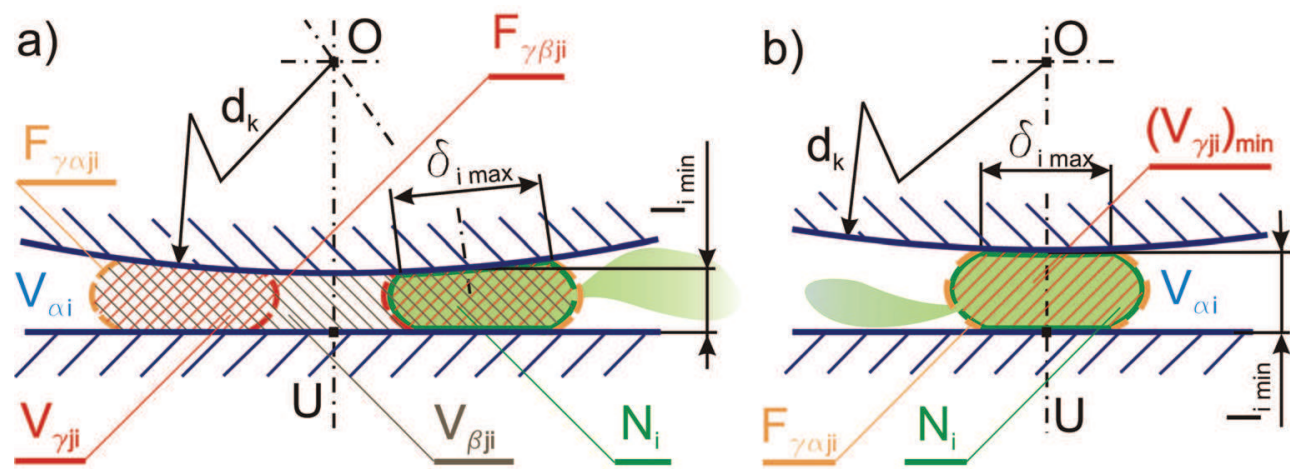

Fig. 2. The model of cell disruption during hitting with spherical elements: a) a general case - a non-axial impact, b) a particular case - an axial impact

In the specific case shown in Fig. 2b, the line of division of space $\mathrm{V}$ is in the AC position (Fig. 1) and volume $\left(\mathrm{V}_{\mathrm{\gamma ji}}\right)_{\mathrm{min}}$ is formed. It is limited by the spherical surface, flat surface and surface $\mathrm{F}_{\gamma \alpha \mathrm{ji}}$ (orange dashed line). The axis of symmetry of volume $\left(\mathrm{V}_{\mathrm{\gamma ji}}\right)_{\min }$ passes through points $\mathrm{O}$ and $\mathrm{U}$.

It follows from the presented phenomenological model that it can encompass not only the working chamber of the mill but even the entire system of technical devices used to disintegrate microorganisms during continuous mill operation. Then volume $V_{\alpha c}$ is composed of suspension volume in the whole system connected to the working chamber including inlet and outlet reservoirs.

\section{A mathematical model}

The concentration of microorganisms introduced into space $\mathrm{V}$ is determined by the initial number of non-transformed cells $\mathrm{N}_{0}$ in space $\mathrm{V}$ according to Eq. (18). 


$$
S=\frac{N_{0}}{V}
$$

For process duration $\mathrm{\tau}=0$ volumes $\mathrm{V}_{\mathrm{\gamma} \mathrm{j},}, \mathrm{V}_{\beta \mathrm{ji}}$ and $\mathrm{V}_{\alpha \mathrm{i}}$ are formed in space $\mathrm{V}$. Unconverted objects can be only in volume $V_{\alpha i}$ appropriate for them. Between safe volumes for particular cells of microorganisms from set $N$ there is a relationship described by Eq. (19).

$$
V_{\alpha b} \subset \ldots \subset V_{\alpha i} \subset \ldots \subset V_{\alpha s}
$$

For the relation given in Eq. (19) equivalence can occur between Eq. (20) and Eq. (21).

$$
\begin{aligned}
& \left(V_{\gamma s}\right)_{\text {min }}=\left(V_{\gamma b}\right)_{\text {min }} \Rightarrow V_{\alpha s}=V_{\alpha b} \\
& \left(V_{\gamma s}\right)_{\text {min }}<\left(V_{\gamma b}\right)_{\min } \Rightarrow V_{\alpha b}<V_{\alpha s}
\end{aligned}
$$

In the case illustrated by Eq. (20) identical cells of microorganisms belonging to set $N$ are uniformly dispersed in the whole volume $\bigcup V_{\alpha i}$. On the other hand, from the equivalence given in Eq. (21) follows the inequality of dispersion of the objects from set $N$ in volume $\bigcup V_{\alpha i}$. Every additional surface $\mathrm{F}_{\gamma \beta \mathrm{i}}$ introduced in space $\mathrm{V}$ additionally separates volume $\bigcup V_{\alpha i}$ into two parts. They differ in the concentration of microorganisms which they contain. The process of ideal mixing ensures uniformity of the dispersion of objects from set $N$ only within the volume limited by the surface of type $\mathrm{F}_{\gamma \beta}$. In the case presented in Eq. (21), owing to relations given in Eq. (2) and (22) and uniform dispersion of elements of set $N$ and volume $\mathrm{V}_{\mathrm{\gamma ji}}$ in space $\mathrm{V}$, we can use mean concentration of dispersed material objects.

$$
\left(V_{\gamma j i}\right)_{\min }<<V
$$

Hence, after starting the process, appropriate objects $\mathrm{N}_{i}$ of set $N$ will be introduced at random to the formed volumes $\mathrm{V}_{\mathrm{\gamma ji}}$. Mean concentration of the transformed objects in the volume occupied by them is described by Eq. (23).

$$
S_{\alpha}=\frac{N_{0}}{V_{\alpha \cup}}
$$

In instant $\tau=0$ of the process duration the number of unconverted objects $N(\tau)$ present in volume $\bigcup V_{\alpha i}$ is equal to the initial number of objects $\mathrm{N}_{0}$, as described by Eq. (24).

$$
N=N_{0}
$$

The number of cells $\mathrm{N}_{\mathrm{d}}(\tau)$ which were disrupted in instant $\tau=0$ is given by Eq. (25).

$$
N_{d}=0
$$

The conversion rate of microorganisms $X(\tau)$ defined by the ratio of the number of disrupted cells $\mathrm{N}_{\mathrm{d}}$ to the initial number of cells $\mathrm{N}_{0}$ according to Eq. (26) is equal to 0 .

$$
X=\frac{N_{d}}{N_{0}}
$$


At any time of the process duration $\tau$ the number of transformed microorganisms is $\mathrm{N}_{\mathrm{d}}$. The transformed cells can be in any place in space $\mathrm{V}$. The number of living microorganisms present only in volume $\bigcup V_{\alpha i}$ is determined by Eq. (27).

$$
N=N_{0}-N_{d}
$$

According to Eq. (28), after time $\tau$ of the process, microbial cells at mean concentration $S_{\alpha}$ determined by number $\mathrm{N}$ of unconverted cells in volume $\bigcup V_{\alpha i}$ are introduced to all volumes $\mathrm{V}_{\mathrm{\gamma ji}}$.

$$
S_{\alpha}=\frac{N}{\bigcup_{\mathrm{i}=1}^{\mathrm{n}} \mathrm{V}_{\alpha \mathrm{i}}}
$$

Naturally, the overall concentration of microorganisms in space V will be determined by Eq. (29). The concentration will be recorded, for instance, in the suspension samples taken from the mill and in the inlet or outlet reservoir.

$$
S=\frac{N}{V}
$$

The rate of conversion of microorganisms after time $\tau$ of the process is given by Eq. (26).

The increase of the number of transformed objects $d_{\mathrm{d}}$ in all volumes $V_{\mathrm{\gamma ji}}$ after arbitrarily short time interval $d \tau$ is specified by Eq. (30).

$$
d N d=S_{\alpha} d V
$$

Volume $\mathrm{dV}$ displaced from $\mathrm{V}_{\mathrm{\alpha j \textrm {j }}}$ to $\mathrm{V}_{\mathrm{\gamma j \textrm {i }}}$ in time increment $\mathrm{d \tau}$ depends on the size of limiting surface $\mathrm{F}$ through which $\mathrm{dV}$ is displaced and on the displacement rate $\mathrm{u}$. This is described by Eq. (31).

$$
d V=u F d \tau
$$

Upon substitution of Eq. (28) and (31) to Eq. (30) we obtain Eq. (32) which describes the increase of objects transformed in volumes $\mathrm{V}_{\mathrm{\gamma j \textrm {i }}}$.

$$
d N_{d}=k N d \tau
$$

The process rate constant $\mathrm{k}$ of the transformation of microbial cells is described by Eq. (33).

$$
k=\frac{F}{\bigcup_{i=1}^{n} V_{\alpha i}} u
$$

Surface $F$ is the sum of these parts of surface $F_{\gamma \alpha j i}$ through which microbial cells pass to volume $\mathrm{V}_{\mathrm{\gamma j} \text {. }}$

Based on Eq. (33) the loss of non-transformed objects can be represented by Eq. (34).

$$
d N=-k\left(N_{0}-N_{d}\right) d \tau
$$




\section{Materials and methods}

Microorganisms were disintegrated in a horizontal bead mill with a multi-disk impeller. The working chamber about $1 \mathrm{dm}^{3}$ in volume had the diameter of $80 \mathrm{~mm}$. The impeller was equipped with six round disks $66 \mathrm{~mm}$ in diameter. They were mounted centrally on the shaft at a distance of $30 \mathrm{~mm}$ from each other. The mill was filled in $80 \%$ with ballotini of the diameter ranging from 0.8 to $1.0 \mathrm{~mm}$. They were made of lead-free glass of specific density around $2500 \mathrm{~kg} / \mathrm{m}^{3} .50 \%$ water solution of ethylene glycol at the temperature $275 \mathrm{~K}$ was supplied to the cooling jacket of the mill. Experiments were carried out in the mill at periodic operating conditions (constant feed). Rotational speed of the impeller was $261.8 \mathrm{rad} / \mathrm{s}$.

The experiments were performed for commercial baker's yeast $S$. cerevisiae produced by Lesaffre Bio-corporation (Wołczyn, Poland). The concentration of yeast suspension ranged from about 0.002 to over $0.17 \mathrm{~g} \mathrm{~d} . \mathrm{m} . / \mathrm{cm}^{3}$. Microorganisms were dispersed in the water solution containing $0.15 \mathrm{M} \mathrm{NaCl}$ and $4 \mathrm{mM} \mathrm{K}_{2} \mathrm{HPO}_{4}$.

The kinetics of cell disruption was determined on the basis of the count of living microorganisms present in the suspension samples. A computer-aided analysis of microscopic images (method I) was used. Cells were counted under the Olympus BX51 microscope (Olympus Optical Co.). Photographs were taken using a CCD digital camera of resolution $2576 \times 1932 \times 24$ bit (Color View III, Soft Imaging System). Preparations were stained with methylene blue. Thom neu chamber (Paul Marienfeld \& Co.) was used to count cells. Photographs were analyzed by means of a specialist software (analySIS 5, Soft Imaging System).

The amount of protein $R$ dissolved in the continuous phase was determined by Bradford's method (1976) (method II). The supernatant was obtained after $20 \mathrm{~min}$ centrifugation at centrifugal force $34000 \mathrm{~g}$. Measurements were made in a spectrophotometer at the wavelength $595 \mathrm{~nm}$ (Lambda 11, Perkin Elmer). A standard protein concentration curve prepared for bovine albumin (Albumin A 9647, Sigma) was applied.

The degree of release of intracellular compounds was analyzed also on the basis of light absorbance A in the supernatant (method III). The measurements were made using a Lambda 11 spectrophotometer (Perkin Elmer) at the wavelength $\lambda=260 \mathrm{~nm}$ (Middelberg et al., 1991; Heim \& Solecki, 1998, 1999). Near the applied wavelength, spectral characteristics of RNA and DNA nucleic acids reach maximum values. The supernatant was obtained after centrifugation of the suspension in a $3 \mathrm{~K} 30 \mathrm{~B}$ centrifuge (Braun Biotech International) for 20 min at centrifugal acceleration of $34000 \mathrm{~g}$. The inside of the centrifuge was cooled down to $4^{\circ} \mathrm{C}$.

In rheological investigations a RC 20 rotational rheometer (RheoTec) operating in a two-slot cylindrical tank - bell-shaped stirrer system was used. Measurements for the suspension of yeast cells and supernatant were made at the temperature $4^{\circ} \mathrm{C}$. The degree of disintegration of microbial cells was changed from 0 to nearly $100 \%$. Supernatant was obtained after 20 minute centrifugation of the suspension at centrifugal force $40000 \mathrm{~g}$.

\section{Results and discussion}

\subsection{Disruption of microbial cells}

In the case monogeneity of yeast cells the set of variable properties $V r$ of objects $N$ is the empty set (Solecki, 2011). At such an assumption the loss of microorganisms $\mathrm{dN}_{\mathrm{d}}$ in time interval $d \tau$ will be expressed by the right-hand side of Eq. (34) with an opposite sign. Kinetics of the disruption of microorganisms in holistic approach is described in Eq. (35). 


$$
d N_{d}=k\left(N_{o}-N d\right) d \tau
$$

Process rate constant $\mathrm{k}$ is described by Eq. (36).

$$
k=\frac{F}{V_{\alpha} \cup} u
$$

The sum of safe volumes $V_{\alpha \cup}$ for subsequent i-th material objects is given by Eq. (37).

$$
V_{\alpha \cup}=\bigcup_{i=1}^{n} V_{\alpha i}
$$

The regression line in Eq. (38) was obtained after integration of Eq. (35) by sides. The integration was preceded by the separation of variables. The regression line is often used to describe the disintegration kinetics of microbial cells in bead mills (Currie et al., 1974; Merffy \& Kula, 1979; Limmon-Lason et al., 1976 Melendres et al., 1991; Garrido et al., 1994; Heim \& Solecki, 1998; Solecki, 2007).

$$
\ln \left(\frac{N_{0}}{N_{0}-N_{d}}\right)=k \tau
$$

A correlation between variables in Eq. (38) was investigated. For linear regression describing the kinetics of yeast cell disruption the values of coefficient $\mathrm{R}$ were higher than 0.9835 . Although advantageous values of the coefficient were obtained, the analysis of rate constant showed significant changes of its value which accompanied changes in the suspension concentration (Fig. 4). They are described by Eq. (39) for the suspension concentration $S>0$.

$$
k=a_{1} S^{2}+a_{2}
$$

When estimating the coefficients in Eq. (39), data for the rate constants much deviating from a model line for very low and low concentrations of the suspension were neglected. Table 1 gives values of the determined coefficients and significant results of statistical analysis.

Changes in the rate constant of cell disruption accompanying a change of the suspension concentration are induced by deviation of the process kinetics from linearity. Their character depends on biomass concentration. In general, three concentration ranges of yeast suspension with similar cell disruption process can be distinguished. These concentrations

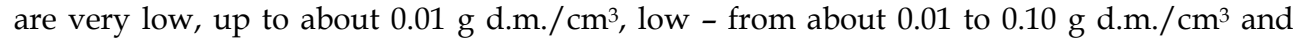

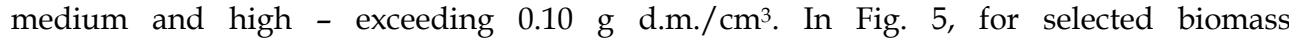
concentrations, the experimentally determined changes in the degree of yeast cell disruption are compared to the changes determined by the linear model (Eq. 38). At low concentrations of the suspension $\left(\mathrm{S}=0.08 \mathrm{~g} \mathrm{~d} . \mathrm{m} . / \mathrm{cm}^{3}\right)$ the process is linear. At the initial stage of the process, at very low suspension concentrations $\left(S=0.002 \mathrm{~g} \mathrm{~d} . \mathrm{m} . / \mathrm{cm}^{3}\right)$, determined values of the rate constant are usually similar to the values obtained for low suspension concentrations. However, when the initial number of cells is small, the disruption rate decreases subsequently during the process. On the other hand, for medium and high concentrations $\left(\mathrm{S}=0.14 \mathrm{~g} \mathrm{~d} . \mathrm{m} . / \mathrm{cm}^{3}\right)$ the process of microbial cell disruption at the initial stage is much slower than the model process. At the next stage of the process the cell disruption rate increases so that the process is much faster than in the case of low concentrations. 


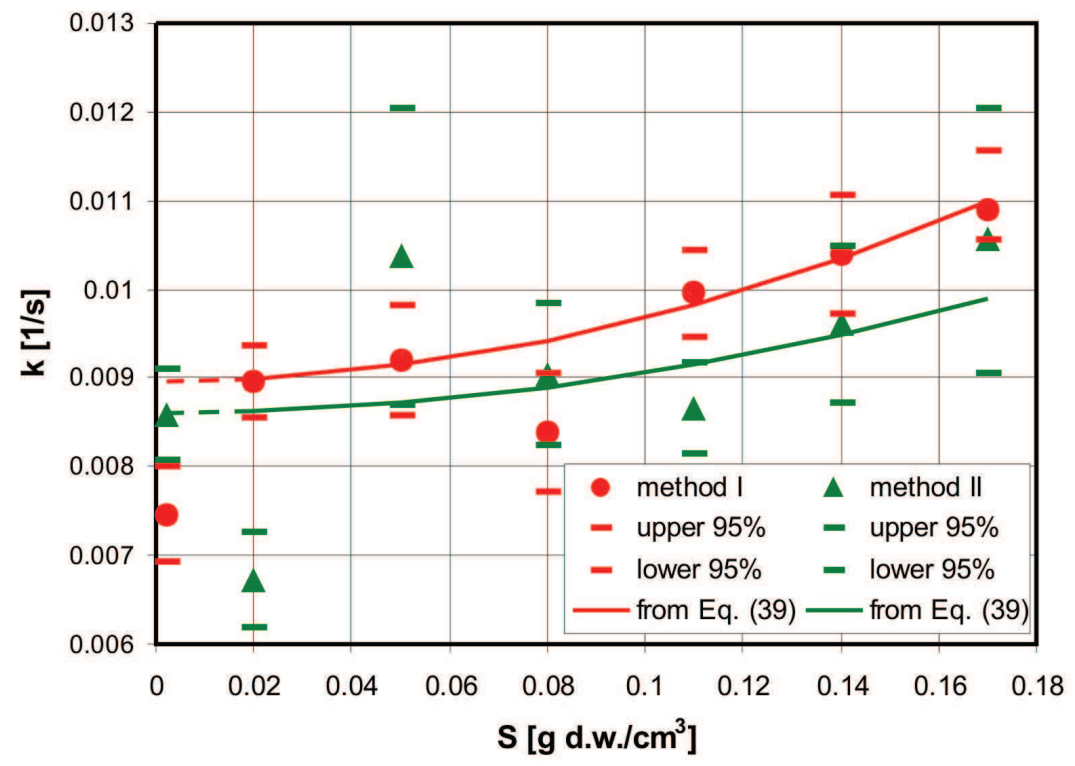

Fig. 3. Changes of rate constant determined for a linear model by method I (direct method based on computer-aided counting of cells under a microscope) and method II (indirect method based on measurement of the quantity of released protein)

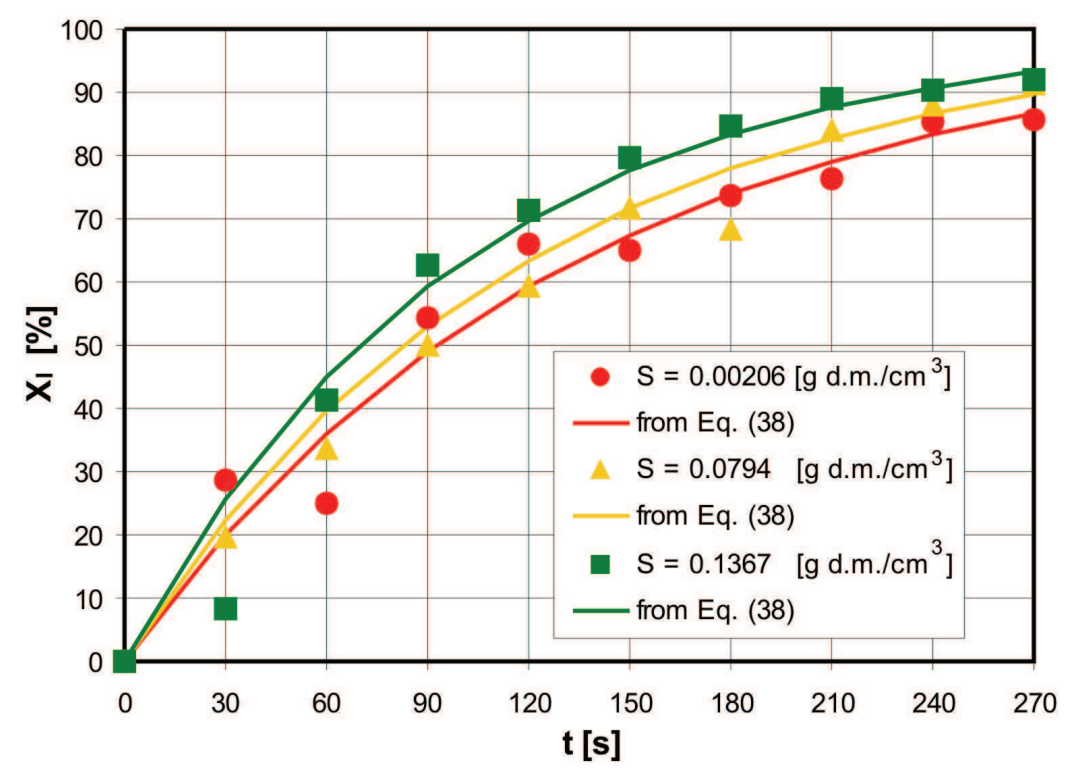

Fig. 4. The effect of suspension concentration on the cell disruption process 


\begin{tabular}{|l|l|l|l|l|}
\hline \multirow{2}{*}{ Method } & $\mathrm{a}_{1}$ & $\mathrm{a}_{2}$ & $\mathrm{n}$ & $\mathrm{R}$ \\
\cline { 2 - 5 } & - & $\mathrm{s}^{-1}$ & - & - \\
\hline I & 0.070 & 0.00897 & 5 & 0,9948 \\
\hline II & 0.045 & 0.0086 & 6 & 0,8812 \\
\hline III & 0.125 & 0.0057 & 5 & 0,9786 \\
\hline
\end{tabular}

Table 1. Results of the estimation of parameters in Eq.(39) for the analytical methods applied

Studies on yeast cell morphology revealed a significant differentiation of cell sizes. Selected parameters are given in Table 2. Size distributions of axes $c_{1 i}$ and $c_{3 i}$ are illustrated in Fig. 5. The process of microbial cell disruption was analyzed taking into account different cell sizes for two cases: in the first one the cells were determined by the short axis of the ellipsoid $\mathrm{c}_{1 i}$, while in the second one by mean diameter $d_{i}$.

\begin{tabular}{|l|l|l|l|l|l|l|l|}
\hline Parameter & $\mathrm{c}_{1 \mathrm{i}}$ & $\mathrm{c}_{3 \mathrm{i}}$ & $\mathrm{d}_{\mathrm{i}}$ & Elongation & $\begin{array}{l}\text { Aspect } \\
\text { ratio }\end{array}$ & $\begin{array}{l}\text { Shape } \\
\text { factor }\end{array}$ & Sphericity \\
\hline unit & $\mu \mathrm{m}$ & $\mu \mathrm{m}$ & $\mu \mathrm{m}$ & - & - & - & - \\
\hline $\min$ & 3.314 & 4.020 & 3.643 & 1.004 & 1.010 & 0.846 & 0.503 \\
\hline $\max$ & 8.007 & 9.433 & 8.686 & 1.432 & 1.439 & 1.126 & 0.992 \\
\hline
\end{tabular}

Table 2. Chosen results of yeast morphology investigations
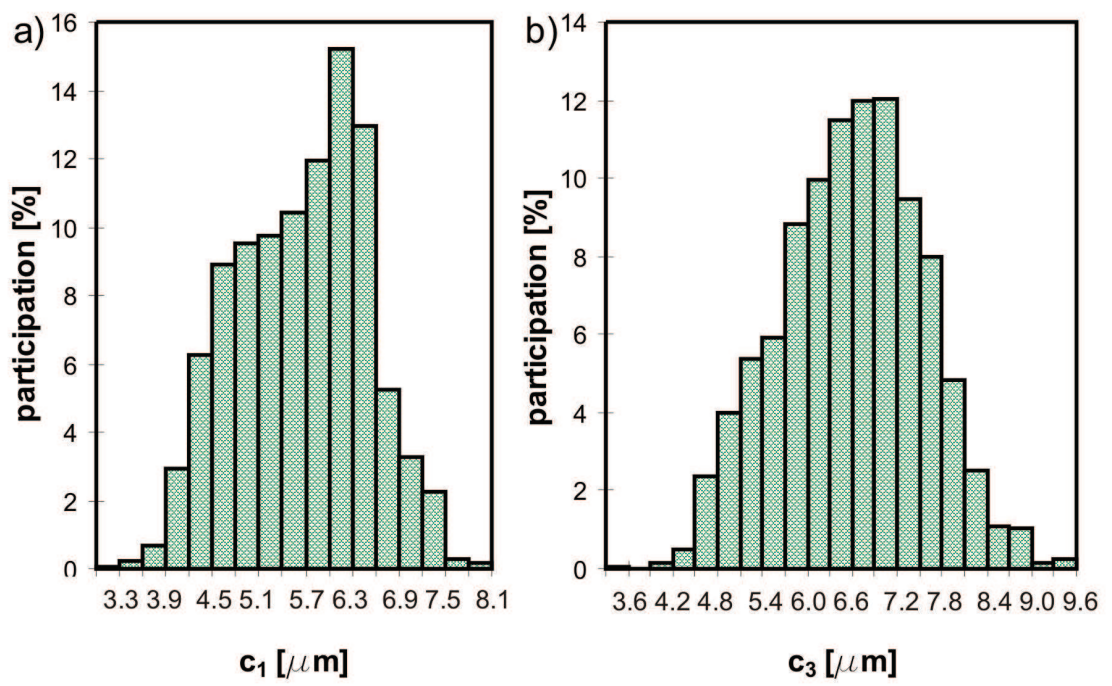

Fig. 5. Distribution of size of small and greater axis ellipsoid defining yeast cells

To model the disintegration process in relation to the size of yeast cells, for both cases mentioned above the set of cells was divided into $m=12$ size fractions. The effect of size fractions on the cell disruption kinetics was investigated using Eq. (35) to describe the disintegration of yeast cells from the given size fraction. This description allowed us to compare the process run in particular fractions with the process taken as whole. Results of the comparison of cell disruption kinetics for particular size fractions determined by mean 
diameter $d_{i}$ are illustrated in Fig. 6 . Values of the rate constant determined for the biggest cell fraction are over 10 times higher than those determined for the smallest cell fraction. Based on the size analysis of undisrupted cells it was found that at a very small initial number of microorganisms during the process three biggest yeast cell fractions disappear successively: 9.5-10 $\mu \mathrm{m}, 9-9.5 \mu \mathrm{m}$ and 8.5-9 $\mu \mathrm{m}$. The process analyzed for size fractions determined by the short axis of the ellipsoid did not reveal any effect of the cell size on microorganism disruption kinetics. This result is a consequence of a significant differentiation of cell sizes determined by the short axis of the ellipsoid. Cells in the given fraction can have the shape almost spherical to ellipsoidal with the $1: 1.4$ axis ratio (Table 2). The same percent deformation along axis $c_{1 i}$ can be destructive for spherical cells but is still safe for much elongated cells.

Solecki (2011) considered the case of random transformation of objects from set $N$ which differed by only one feature $v r_{1}$ having an important effect on the process. Eq. (40) describes the transformation of objects from an arbitrary interval $\zeta \in\langle 1, m\rangle$ taking into account the existence of the whole set $N$.

$$
\frac{N_{0 \zeta}}{N_{0}} d N_{d \zeta}=\frac{N_{0 \zeta}}{N_{0}} k_{\zeta}\left(N_{0 \zeta}-N_{d \zeta}\right) d \tau
$$

Eq. (41) describes the transformation of objects of the entire set taking into consideration the division of set $N$ into subsets.

$$
\sum_{\zeta=1}^{m} \frac{N_{0 \zeta}}{N_{0}} d N_{d \zeta}=\sum_{\zeta=1}^{m} \frac{N_{0 \zeta}}{N_{0}} k_{\zeta}\left(N_{0 \zeta}-N_{d \zeta}\right) d \tau
$$

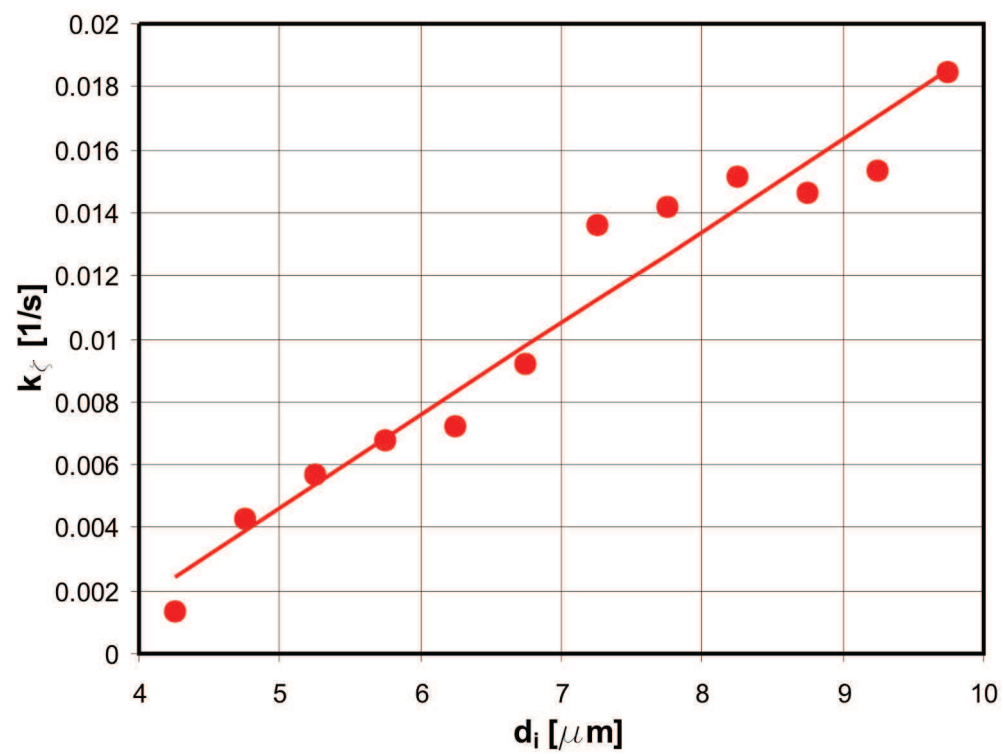

Fig. 6. The effect of cell size on the disintegration rate constant 
After separating the variables in Eq. (41) and integration by sides, we get Eq. (42).

$$
\sum_{\zeta=1}^{m} \frac{N_{0 \zeta}}{N_{0}} \ln \frac{N_{0 \zeta}}{N_{0 \zeta}-N_{d \zeta}}=\sum_{\zeta=1}^{m} \frac{N_{0 \zeta}}{N_{0}} k_{\zeta} \tau
$$

Relations between rate constants in Eq. (35) and (40) are determined in Eq. (43).

$$
\Phi \sum_{\zeta=1}^{m} \frac{N_{0 \zeta}}{N_{0}} k_{\zeta}=k
$$

Coefficient $\Phi$ is described by the relation given in Eq. (44).

$$
\Phi=\ln \frac{N_{0}}{N_{0}-N_{d}}\left(\sum_{\zeta=1}^{m} \frac{N_{0 \zeta}}{N_{0}} \ln \frac{N_{0 \zeta}}{N_{0 \zeta}-N_{d \zeta}}\right)^{-1}
$$

The process of disintegration in the mill is described by Eq. (42) as a total effect of disintegration of particular cell size fractions. The disintegration kinetics of microorganisms in particular fractions is linear. Differences in cell sizes do not cause nonlinearity of the process. Deviations from linearity shown for very low concentrations of the suspension are caused by the decay of subsequent cell size fractions during the process. Nonlinearity of the process obtained at a very small initial number of microorganisms in the suspension $\mathrm{N}_{0}$ described by Eq. (42) is illustrated in Fig. 7.

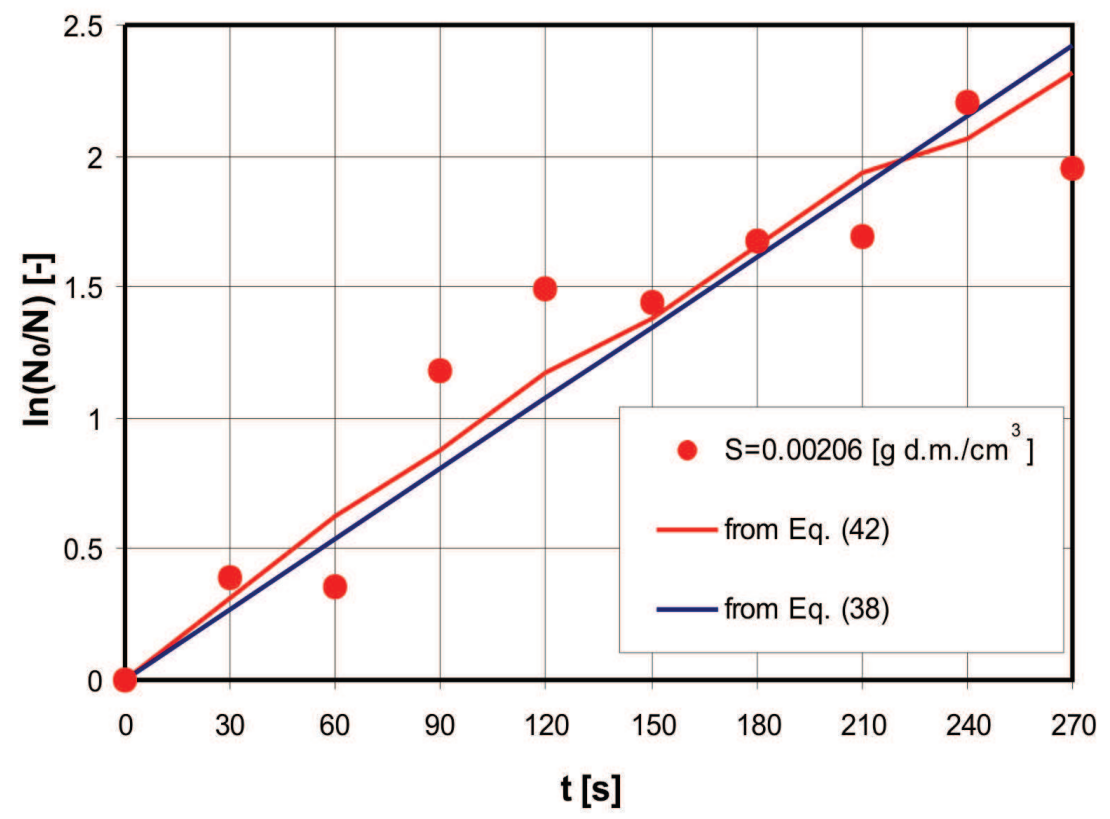

Fig. 7. The course of microbial cell disruption taking into consideration the effect of size fraction on the disintegration rate 
Analysis of results of the process showed that at low concentrations of the suspension $(0.05$ g d.m. $/ \mathrm{cm}^{3}$ ) the process was very well described by linear relation in Eq. (38) $(\mathrm{R}=0.9938)$. The presence of the biggest yeast cells until reaching over $90 \%$ disintegration was confirmed using the direct method. In the case of yeast cell concentration equal to $0.05 \mathrm{~g} \mathrm{~d} . \mathrm{m} . / \mathrm{cm}^{3}$, the initial number of cells is over 20 times bigger than in the case of cell concentration of $0.002 \mathrm{~g}$ d.m. $/ \mathrm{cm}^{3}$. Hence, it is more probable that bigger cells will survive longer in the process at higher concentrations of the suspension.

The disintegration of microorganisms in the bead mill is a random transformation of dispersed matter. If the experiments were carried out for a single cell, it might have appeared that the degree of disintegration obtained in the first experiment would be $100 \%$, in the second one also $100 \%$, and in the third one e.g. $0 \%$. From the investigations carried out for the suspension concentration equal to $0.05 \mathrm{~g} \mathrm{~d} . \mathrm{m} . / \mathrm{cm}^{3}$ it follows that if there are 2,355E9 cells dispersed at one time, after the process 0,2598E9 cells will remain alive on average. Hence, for an experiment carried out with a single cell, in 11 cases out of 100 experiments the result of disintegration at time $\tau=270 \mathrm{~s}$ will be $0 \%$ on average. It is probable, however, that in the process all cells will disintegrate. This probability decreases with an increase of the initial number of cells. Nonlinearity of the process caused by subsequent decay of objects from set $N$ which are most susceptible to transformations can appear at every concentration of the suspension. This probability depends on the initial concentration of microorganisms in the suspension. For very low concentrations it is very big, while for high concentrations it is small. At a very small number of cells, a nonlinear process will be most probable, although it is not likely that the process will be linear. For a small and big number of cells, when no relations occur between the cells, a linear process is expected, but it may also happen that the process will be nonlinear. A result of this phenomenon are rate constants determined experimentally which are smaller than the values determined from the model and given by Eq. (39).

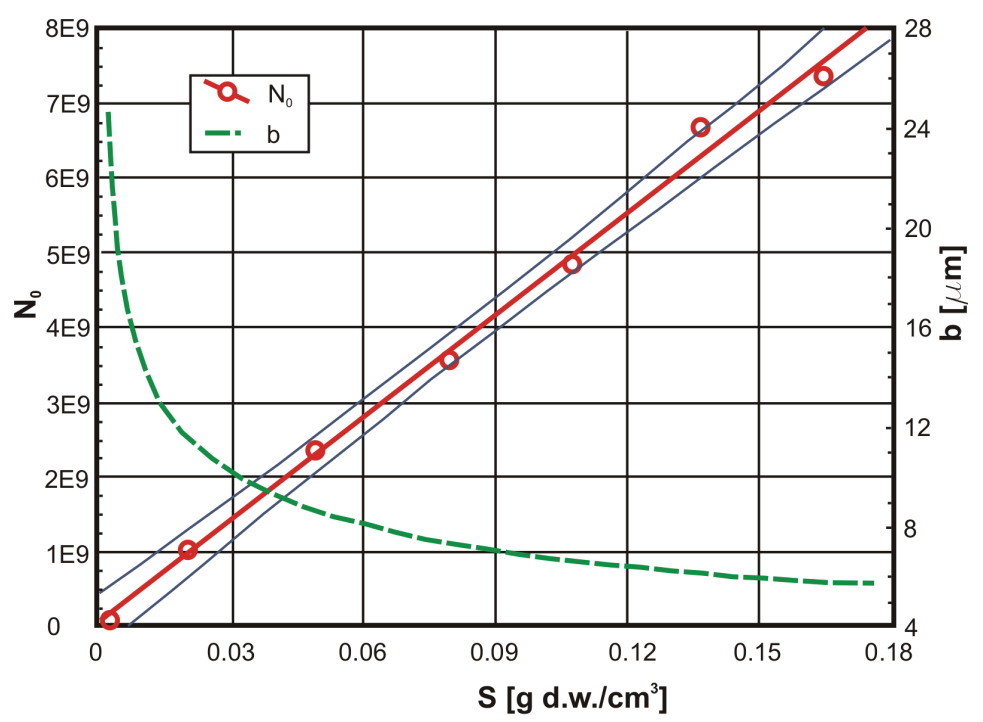

Fig. 8. Influence of suspension density on the distance between geometrical centres of adjacent cells (distribution of yeasts in the nodes of compact hexagonal network was assumed) 
An increase of the initial number of yeast cells in the suspension causes an increase of rate constant k (Fig. 3) according to Eq. (39). Analysis of the phenomenological model of the process shows that this can be due to an increase of volume $V_{\gamma i}$ and consequently the growth of volume $V_{\beta i}$. When microorganisms are concentrated, the interrelations between cells are intensified. That was confirmed by the investigations of the effect of biomass concentration and degree of disintegration on distances between geometric centers of adjacent yeast cells (Heim \& Solecki 1999; Heim et al., 2007). It was assumed that they are placed in the nodes of the compact hexagonal network. Eq. (45) describes relationships of the distances between centers of the adjacent microorganisms b with biomass concentration $S$ and disintegration degree $X$ (Heim et al., 2007).

$$
b=\frac{a_{4}}{[S(1-X)]^{\frac{1}{3}}}+\text { error }
$$

The analysis of yeast cell size distribution and distances between geometric centers of the cells indicated very significant intensification of relationships between the microorganisms, which follows an increase of the concentration of biomass. For instance, at the concentration $0.11 \mathrm{~g} \mathrm{~d} . \mathrm{m} . / \mathrm{cm}^{3}$ about $30 \%$ of the cells show higher value of parameter $\mathrm{c}_{1 \mathrm{i}}$ than distance $\mathrm{b}$ equal to about $6 \mu \mathrm{m}$. The increased intensity of cell interactions is confirmed also by the results of studies on rheological properties of the microbial suspension. It was proved that an increase of the initial concentration of microorganisms caused a decrease of apparent viscosity of the suspension. At the concentration $0.002 \mathrm{~g} \mathrm{d.m} . / \mathrm{cm}^{3}$ its value is close to that obtained for water, at $0.08 \mathrm{~g} \mathrm{d.m.} / \mathrm{cm}^{3}$ it is about $5 \mathrm{mPas}$, and at the concentration $0.17 \mathrm{~g}$ d.m. $/ \mathrm{cm}^{3}$ it reaches $20 \mathrm{mPas}$.

During the disintegration of yeast cells significantly changed the rheological properties of the suspension. Interesting is a rapid decrease of the apparent viscosity at the initial stage of the process at $\tau=0-30 \mathrm{~s}$, related to the destruction of a large number of spatial structures of yeast cells. The cell disruption rate increases at a later stage of the process. According to the results shown in Fig. 5, the rate of disintegration increases in the process time ranging from 30 to around $120 \mathrm{~s}$.

The presented analysis of relationships refers to the suspension of yeast cells placed in an ordinary reservoir. The concentration of microorganisms in space $\mathrm{V}$ is generally described by Eq. (29). After supplying the suspension into the mill working chamber, the relationships between cells are further intensified. Particular cells $N_{i}$ fill up only volumes $V_{\text {ai, }}$ while the continuous phase fills also volumes $\mathrm{V}_{\gamma \mathrm{ji}}$ and $\mathrm{V}_{\beta \mathrm{ji}}$. When the suspension is fed into the mill, the cells are filtered in volumes $V_{\alpha i}$. With the moment of starting the process, the suspension of mean concentration $S_{\alpha}$ is introduced to volume $V_{\mathrm{\gamma ji}}$ according to Eq. (28).

The above analyses lead to a conclusion that an increase of volume $V_{\gamma i}$ which causes an increase of the cell disruption rate cannot be induced by yeast blocking by adjacent cells. Such an effect could be brought about by released intracellular compounds or some fragments of already disrupted cells. Nonlinearity of the process, which is revealed with an increase of suspension concentration, is described by Eq. (46) (Heim et al., 2007). It takes into account the concentration of the suspension of microorganisms and the change of distance between centers of adjacent cells which occurs during the process. A change of parameter $b$ for a given concentration of the suspension is the measure of the number of disrupted cells and released intracellular compounds. 


$$
\ln \frac{N_{0}}{N}=k\left[1+\left(\frac{S}{b}\right)^{a_{5}}\right] t
$$

The process rate for high suspension concentrations increases only at the second stage of the process, after over $30 \mathrm{~s}$. At the initial phase, the process is slower than the disruption of microorganisms at the concentration of $0.05 \mathrm{~g} \mathrm{d.m.} / \mathrm{cm}^{3}$ (Fig. 4). Such a result was obtained at $0.11,0.14$ and $0.17 \mathrm{~g} \mathrm{d.m./} / \mathrm{cm}^{3}$. The decreased process rate is caused by inefficient operation of the packing in the working chamber. If packing of the cells is so dense as that described above, the approaching surfaces cause deformation of the compressed cell perpendicular to the destruction axis. A result is forcing out of adjacent cells from the hazardous zone and consequently, a decreased efficiency of the packing. In this case, the relative rate of cell supply does not only result from cell concentration and the dislocation rate of the suspension.

\subsection{The release of intracellular compounds}

In the case when cell disruption is equivalent to the release of intracellular compounds, the kinetics of protein release R from yeast cells is described by Eq. (47).

$$
d R=k_{I I}\left(R_{m}-R\right) d \tau
$$

The values of absorbance obtained at a given concentration of individual samples were calculated into the amount of pure nucleic acid RNA released during the process from the cells. Its concentration in the continuous phase of the suspension after time of the process is denoted as $\mathrm{C}$. The calculations were made after assuming mean values for nucleotides defined by Benthin et al. (1991). Taking into account the method of analysis of disintegrated microorganisms, a mathematical description of the process has the form of Eq. (48).

$$
d C=k_{I I I}\left(C_{m}-C\right) d \tau
$$

A maximum concentration of protein $R_{m}$ and nucleic acids $C_{m}$ was determined in separate experiments based on the quantities of released intracellular compounds specified for cell disintegration level ranging from about $98 \%$ to over $99 \%$. Experiments performer at the disintegration range $0-90 \%$ are represented according to the method applied by the regression line given by Eq. (49) or Eq. (50), respectively.

$$
\begin{aligned}
& \ln \left(\frac{R_{m}}{R_{m}-R}\right)=k_{I I} \tau \\
& \ln \left(\frac{C_{m}}{C_{m}-C}\right)=k_{I I I} \tau
\end{aligned}
$$

When measuring method II was used, the values of coefficient $\mathrm{R}$ for data obtained in subsequent experiments were not smaller than 0.9605, while in the case of method III not smaller than 0.9826 . The determined values of the rate constant of protein release are given in Fig. 3. Changes of this rate constant which proceed with concentration growth are in agreement with the dependence of yeast cell disruption rate constant on cell concentration. Rates constants of protein release at the highest concentration are about 1.5 times bigger 
than the values obtained for the lowest yeast cell concentration. A similar relation and character of changes were obtained when the release of intracellular compounds was studied on the basis of absorbance measurements. Results of these experiments are illustrated in Fig. 9. At suspension concentration $S>0$ changes of the process rate constant in methods II and III are described by Eq. (39) and results of estimation are collected in Table 1. Data obtained by Bradford's method for concentrations 0.02 and 0.05 were deleted from statistical analyses; in the case of absorbance measurements data obtained for the lowest concentration of the suspension were omitted.

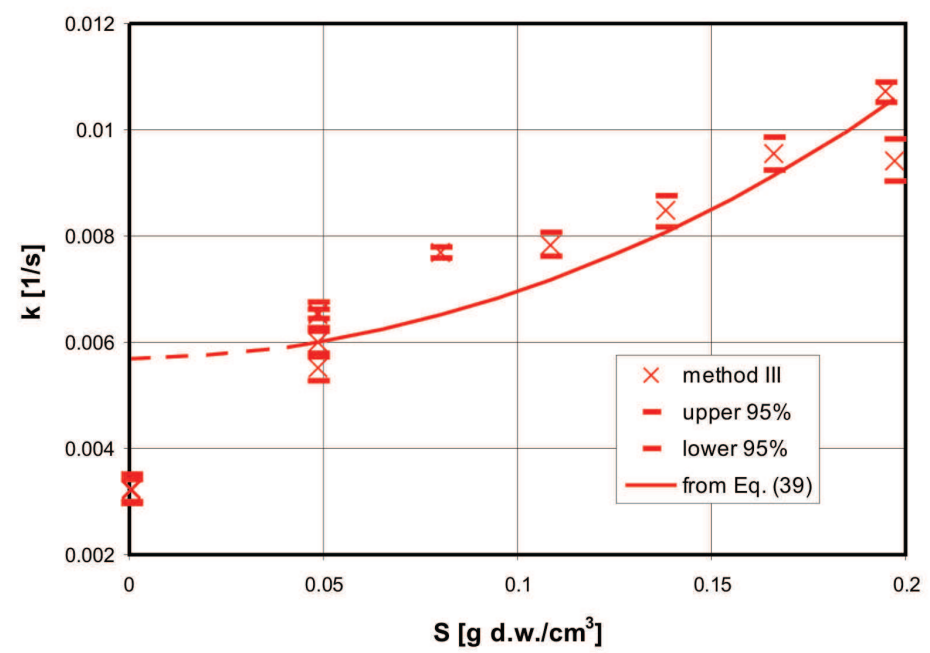

Fig. 9. Changes of rate constant determined for a linear model - method III

Results shown in Fig. 3 refer to biological material taken from one fermentation process, while these illustrated in Fig. 9 were obtained for yeast from a different fermentation process. In general, the results show that protein release is slower than microbial cell disruption. These observations are in agreement with results obtained by Middelberg et al. (1991) for Escherichia coli disintegrated in a high-pressure homogenizer. For such bacteria whose cellular structure is different than yeast cellular structure, the authors showed that the process tested on the basis of determination of the number of living microorganisms and absorbance of light with the wavelength $260 \mathrm{~nm}$. According to Middelberg et al. (1991), the process of protein release measured also by Bradford's method is slower. Dependence of the release rate of intracellular compounds on the place of their location in cells was published by Hetherington et al. (1971). The authors report that during disintegration of E. coli cells the periplasmic enzymes are released faster than total protein, all cytoplasmic enzymes are released at the same rate as total protein, whereas membrane-bound enzyme slower.

The release of intracellular compounds during disintegration of microorganisms in the bead mill is shown in Figs 10 and 11. In general, the results are concordant with the results obtained in the experiments with cell disruption process. A decreased rate of protein release at the initial stage of disintegration is observed already at low suspension concentrations; it is higher than the decrease of cell disruption rate at medium and high concentrations of the suspension. Character of the process investigated on the basis of absorbance measurement is 


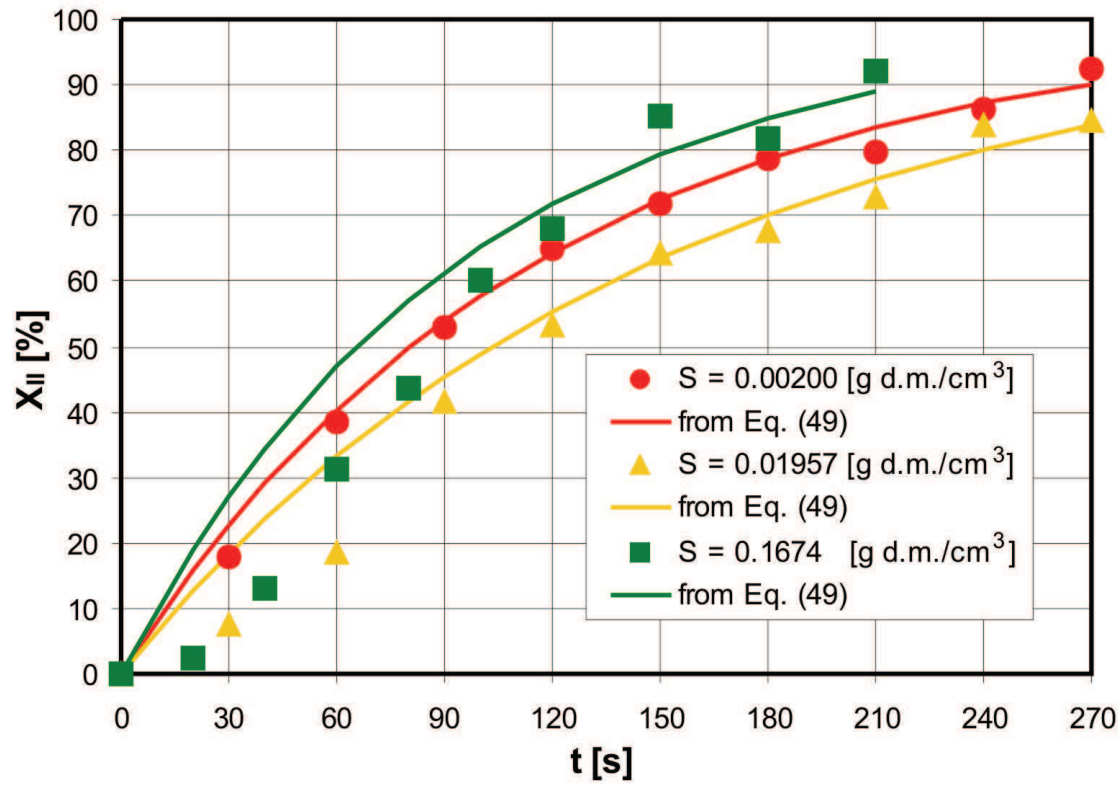

Fig. 10. The effect of suspension concentration on the protein release process

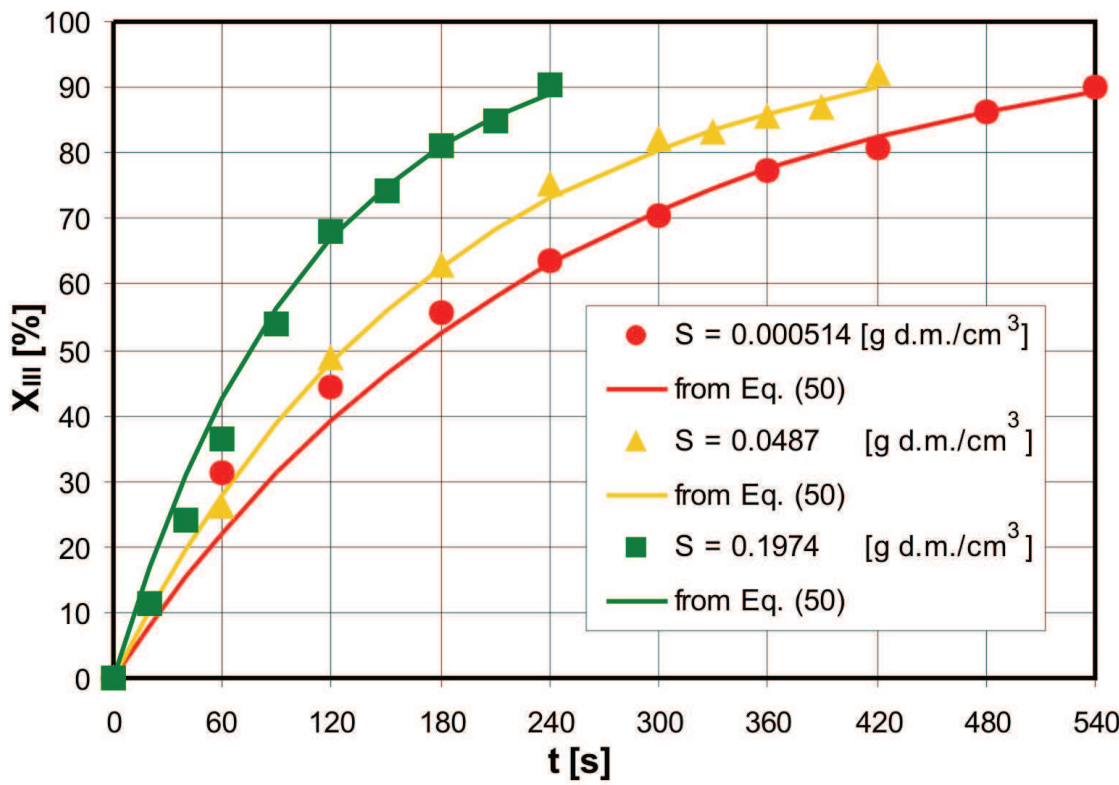

Fig. 11. The effect of suspension concentration on the intracellular compounds release process 
close to the one obtained on the basis of determination of the number of living cells. In the case of high suspension concentrations the decrease of the intracellular compound release rate was not so significant as in the case of results obtained by the direct measuring method. The sequence of events: cell wall disruption - release of intracellular compounds, was used by Melendres et al. (1993) to describe nonlinear release of enzymes. This theory can be used in the description of total protein release. Eq. (35) can be written in the form of Eq. (51).

$$
N_{d}=N_{0}\left(1-e^{-k t}\right)
$$

If protein release rate is proportional to that which can be released from disrupted cells, the increment of protein released in time $\mathrm{d} \tau$ is described by Eq. (52).

$$
d R=k_{I I}\left(R_{D}-R\right) d \tau
$$

Protein can be released only from disrupted cells. The maximum amount of protein $R_{D}$ that can be released from cells disrupted in time $\tau$ is specified by Eq. (53).

$$
R_{D}=R_{m}\left(\frac{N_{d}}{N_{0}}\right)
$$

Upon substitution of Eq. (53) and Eq. (51) to Eq. (52) we obtain Eq. (54) for protein release in the process of microbial cell disruption.

$$
d R=k_{I I}\left[R_{m}\left(1-e^{-k \tau}\right)-R\right]
$$

Results illustrated in Fig. 4 show that differences in the process rates increase with an increase of the concentration of microorganism suspension. Character of changes of the rate constants determined on the basis of absorbance measurements is in agreement with that revealed on the basis of computer-aided analysis of microscopic images and Bradford's method (1976).

\section{Conclusions}

Disintegration of microorganisms in bead mills is the process of random transformation of organic matter dispersed in limited space. The general theory can be used to formulate a phenomenological model of the disintegration process and its mathematical description. They allow us to illustrate fundamental phenomena and mechanisms of the tested process. The presented method of modeling allows us to analyze many factors that have an influence on the kinetics of transformations, for instance such as different sizes, strength and morphological forms of cells.

The disintegration of microorganisms covers the process of cell disruption and subsequent release of intracellular compounds contained in the cells. The discussed results of experiments proved that the size of cells of microorganisms of the same species had an effect on microorganism disintegration rate. A subsequent loss of the biggest size fractions during the process causes nonlinearity of cell disruption kinetics. The probability of decay of the biggest cell size fractions at a very low concentration of microorganisms is very high. It decreases with an increase of the concentration of microbial suspensions.

In the packing of the mill working chamber, with an increase of the suspension concentration increases also intensity of intercellular relations due to filtering of 
microorganisms in the space which is safe for them. At high and very high concentrations, cells deformed due to compression can force out adjacent cells from the destruction zone causing a decrease of the process rate at its initial stage. An increase of the rates of cell disruption and release of intracellular compounds at medium and high concentration of microbial suspensions can be caused by mutual blocking of cells, blocking of cells by fragments of disintegrated microorganisms or the interaction of released intracellular compounds. Results of the discussed investigations confirmed the dependence of compound release rates on the position of these compounds in a cell.

\section{Acknowledgments}

The study was carried out within the frames of the grant W-10/1/2011/Dz. St.

\section{References}

Benthin, S., Nielsen, J. \& Villadsen, J. (1991). A Simple and Reliable Method for the Determination of Cellular RNA Content. Biotechnology Techniques, Vol.5, No.1, pp. 39-42, ISSN 0951-208X

Bradford, M.M. (1976). A Rapid and Sensitive Method for the Quantitation of Microgram Quantities of Protein Utilizing the Principle of Protein-Dye Binding. Analytical Biochemistry, Vol.72, pp. 248-254, ISSN 0003-2697

Chen, J., Chen, H. and Gong, X. (1997). Mixotrophic and heterotrophic growth of Haematococcus lacustris and rheological behaviour of the cell suspensions. Bioresource Technology, Vol.62, pp. 19-24, ISSN 0960-8524

Chisti, Y. \& Moo-Young, M. (1986). Disruption of microbial cells for intracellular products. Enzyme and Microbial Technology, Vol. 8, pp. 194-204, ISSN 0141-0229

Currie, J.A., Dunnil, P. \& Lilly, M.D. (1972). Release of protein from bakers' yeast (Saccharomyces cerevisiae) by disruption in an industrial agitator mill. Biotechnology and Bioengineering, Vol.14, pp. 723-736, ISSN 0006-3592

Geciova, J., Bury, D. \& Jelen, P. (2002). Methods for disruption of microbial cells for potential ues in the dairy industry - a review. International Dairy Journal, Vol. 12, pp. 541-553, ISSN 0958-6946

Garrido, F., Banerjee, U.C., Chisti, Y. \& Moo-Young, M. (1994). Disruption of recombinant yeast for the release of $\beta$-galactosidase. Bioseparation, Vol.4, pp. 319-328, ISSN 0923$179 X$

Hatti-Kaul, R. \& Mattiasson, B. (2003). Release of protein from biological host, in Hatti-Kaul, R. \& Mattiasson, B. (eds), Isolation and purification of proteins, Marcel Deker, Inc, New York, Basel, pp. 22-49, ISBN 0-8247-0726-5

Hartmann, C., Mathmann, K. \& Delgado, A. (2006). Mechanical stresses in cellular structures under high hydrostatic pressure. Innovative Food Science and Emerging Technologies, Vol.7, pp.1 - 12, ISSN 1466-8564

Heim, A., Kamionowska, U. \& Solecki, M. (2007). The effect of microorganism concentration on yeast cell disruption in a bead mill. Journal of Food Engineering, Vol.83, pp. 121128, ISSN 0260-8774

Heim, A. \& Solecki, M. (1998). Disintegration of microorganisms in a circulating bed of balls. Proceedings of World Congress on Particle Technology 3, ISBN 0-85295-401-8, Brighton UK, July 1998 
Heim, A. \& Solecki, M., (1999). Disintegration of microorganisms in bead mill with a multidisc impeller. Powder Technology, 105, 390-396, ISSN 0032-5910

Hetherington, P. J., Follows, M., Dunnill, P. \& Lilly, M. D. (1971). Release of protein from baker's yeast (Saccharomyces cerevisiae) by disruption in an industrial homogeniser. Transactions of the Institution of Chemical Engineers, Vol.49, pp. 142-148, ISSN 00469858

Limon-Lason, J., Hoare, M., Orsborn, C.B., Doyle, D.J. \& Dunnill, P. (1979). Reactor properties of a high-speed bead mill for microbial cell rupture. Biotechnology and Bioengineering, Vol.21, pp. 745-774, ISSN 0006-3592

Marffy, F. \& Kula, M.R. (1974). Enzyme yields from cells of brewer's yeast disrupted by treatment in a horizontal disintegrator. Biotechnology and Bioengineering, Vol.16, pp. 623-634, ISSN 0006-3592

Mashmoushy, H., Zhang, Z. \& Thomas, C.R. (1998). Micromanipulation measurement of the mechanical properties of baker's yeast cells. Biotechnology Techniques, Vol.12, No.12, pp. 925-929, ISSN 0951-208X

Melendres, A.V., Honda, H., Shiragam, N. \& Unno, H. (1991). A kinetic analysis of cell disruption by bead mill. Bioseparation, Vol.2, pp. 231-236, ISSN 0923-179X

Melendres, A.V., Honda, H., Shiragami, N. \& Unno, H. (1993). Enzyme release kinetics in a cell disruption chamber of a bead mill. Journal of Chemical Engineering of Japan, Vol.26 No.2, pp. 148-152, ISSN 0021-9592

Middelberg, A.P.J., O'Neill, B.K. \& Bogle D.L. (1991). A novel technique for the measurement of disruption in high-pressure homogenization: studies on E. coli containing recombinant inclusion bodies. Biotechnology and Bioengineering, Vol.38, pp. 363-370, ISSN 0006-3592

Shiu, C. Zhang, Z. \& Thomas, C.R. (1999). A novel technique for the study of bacterial cell mechanical properties, Biotechnology Techniques, Vol.13, pp. 707-713, ISSN 0951-208X

Smith, A.E., Moxham, K.E., Middelberg, A.P.J. (1998). On uniquely determining cell-wall material properties with the compression experiment, Chemical Engineering Science, Vol.53, pp. 3913-3922, ISSN 0009-2509

Smith, A.E., Zhang, Z. \& Thomas, C.R. (2000). Wall material properties of yeast cells: Part 1. Cell measurements and compression experiments, Chemical Engineering Science, Vol.55, pp. 2031-2041, ISSN 0009-2509

Solecki, M. (2007). Yeast disintegration in a bead mill. Chemical and Process Engineering, Vol.28, 649-660, ISSN 02508-64

Solecki, M. (2009). Modeling of microorganism disintegration in spherical packing of a bead mill. Proceedings of 5th International Conference for Conveying and Handlings of Particulate Solids, ISBN 978-0858 259 065, Brisbane Australia, August 2009

Solecki, M. (2011). The theory of random transformation of dispersed matter. (unpublished)

Stenson, J.D., Ren, Y., Donald, A.M. \& Zhang, Z. (2010). Compression testing by nanomanipulation in environmental scanning electron microscope. Experimental Techniques, Vol.34, No.2, pp. 60-62, ISSN 1747-1567

Svaldo-Lanero, T., Krol, S., Magrassi, R., Diaspro, A., Rolandi, R. Gliozzi, A. \& Cavalleri, O. (2007). Morphology, mechanical properties and viability of encapsulated cells. Ultramicroscopy, Vol.107, pp. 913-921, ISSN 0304-3991

Whitworth, D.A. (1974). Hydrocarbon fermentation: protein and enzyme solubilization from C. lipolytica using an industrial homogenizert. Biotechnology and Bioengineering, Vol. 16, pp. 1399-1406, ISSN 0006-3592 


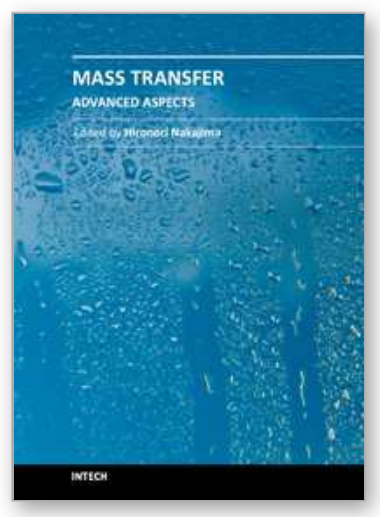

\author{
Mass Transfer - Advanced Aspects \\ Edited by Dr. Hironori Nakajima
}

ISBN 978-953-307-636-2

Hard cover, 824 pages

Publisher InTech

Published online 07, July, 2011

Published in print edition July, 2011

Our knowledge of mass transfer processes has been extended and applied to various fields of science and engineering including industrial and manufacturing processes in recent years. Since mass transfer is a primordial phenomenon, it plays a key role in the scientific researches and fields of mechanical, energy, environmental, materials, bio, and chemical engineering. In this book, energetic authors provide present advances in scientific findings and technologies, and develop new theoretical models concerning mass transfer. This book brings valuable references for researchers and engineers working in the variety of mass transfer sciences and related fields. Since the constitutive topics cover the advances in broad research areas, the topics will be mutually stimulus and informative to the researchers and engineers in different areas.

\title{
How to reference
}

In order to correctly reference this scholarly work, feel free to copy and paste the following:

Marek Solecki (2011). The Release of Compounds from Microbial Cells, Mass Transfer - Advanced Aspects, Dr. Hironori Nakajima (Ed.), ISBN: 978-953-307-636-2, InTech, Available from:

http://www.intechopen.com/books/mass-transfer-advanced-aspects/the-release-of-compounds-from-microbialcells

\section{INTECH}

open science | open minds

\section{InTech Europe}

University Campus STeP Ri

Slavka Krautzeka 83/A

51000 Rijeka, Croatia

Phone: +385 (51) 770447

Fax: +385 (51) 686166

www.intechopen.com

\section{InTech China}

Unit 405, Office Block, Hotel Equatorial Shanghai

No.65, Yan An Road (West), Shanghai, 200040, China

中国上海市延安西路65号上海国际贵都大饭店办公楼 405 单元

Phone: +86-21-62489820

Fax: $+86-21-62489821$ 
(C) 2011 The Author(s). Licensee IntechOpen. This is an open access article distributed under the terms of the Creative Commons Attribution 3.0 License, which permits unrestricted use, distribution, and reproduction in any medium, provided the original work is properly cited. 